\title{
PENGARUH PEMBERIAN EKSTRAK BIJI PEPAYA (CARICA PAPAYA L.) TERHADAP KUALITAS SPERMATOZOA TIKUS WISTAR (RATTUS NORVEGICUS)
}

\author{
${ }^{1}$ Rionaldy Walansendow \\ ${ }^{2}$ Janette M. Rumbajan \\ ${ }^{2}$ Lydia Tendean
}

\author{
${ }^{1}$ Kandidat Skripsi Fakultas Kedokteran Universitas Sam Ratulangi \\ ${ }^{2}$ Bagian Biologi Fakultas Kedokteran Universitas Sam Ratulangi \\ Email: rionaldy1996@yahoo.com
}

\begin{abstract}
Participation of men on using contraceptive is still low. Carica papaya L. contains alkaloid chemicals which act as antifertility agent and can be used as contraceptives for men. This study was carried out to find the effects of Carica papaya L. seed extracts toward the spermatozoa qualities. This study was conducted to nine male wistar rats (Rattus norvegicus) weighing from 200 to 250 grams, aging from 12 to 15 months. These nine healthy adult rats were divided into 3 groups of 3 rats each. 50 and $70 \mathrm{mg} / \mathrm{kg} /$ day of the extract were orally administrated to group 1 and 2 respectively, while group 3 were treated as a negative control group. The daily administration was carried out for 50 days, after which the animals of group 1,2 and 3 were sacrificed. This study found a decreased quality of spermatozoa (i.e morphology) in group 1 and 2 ( $p=0,000)$. Thus, confirms it's contraceptive efficacy on men's fertility.
\end{abstract}

Keywords: carica papaya l. seed, spermatozoa

\begin{abstract}
Partisipasi pria dalam menggunakan alat kontrasepsi masih kurang. Tanaman pepaya mengandung senyawa alkaloid yang bersifat antifertilitas dan dapat digunakan sebagai bahan untuk kontrasepsi pria. Tujuan dari penelitian ini adalah untuk mengetahui pengaruh dari ekstrak biji pepaya (Carica papaya L.) terhadap kualitas spermatozoa. Penelitian eksperimental ini dilakukan pada sembilan ekor tikus wistar jantan (Rattus norvegicus) dengan berat badan 200-250 gram berumur 12-15 bulan. Sembilan ekor wistar dibagi menjadi tiga kelompok, dan satu kelompok terdiri dari tiga ekor tikus wistar. Selama 50 hari, ekstrak biji pepaya (Carica papaya L.) diberikan pada kelompok perlakuan 1 sebesar $50 \mathrm{mg} / \mathrm{kgBB}$ per hari, sedangkan pada kelompok perlakuan 2 sebesar 70 mg/kgBB per hari. Kelompok kontrol tidak diberikan perlakuan. Setelah 50 hari hewan coba pada kelompok kontrol, perlakuan 1, dan perlakuan 2 diterminasi. Hasil penelitian menunjukkan terjadi penurunan kualitas spermatozoa berupa morfologi spermatozoa pada tikus wistar yang diberikan ekstrak biji papaya (Carica papaya L.) (p = 0,000). Hasil tersebut menunjukkan bahwa ekstrak biji pepaya mempunyai efek antifertilitas terhadap fertilitas pria.
\end{abstract}

Kata kunci: biji pepaya, spermatozoa

Program keluarga berencana (KB) merupakan suatu usaha untuk menjarangkan atau merencanakan jumlah dan jarak kehamilan dengan memakai kontrasepsi. Secara umum, salah satu tujuan dari program KB adalah membentuk keluarga kecil sesuai dengan kekuatan sosial ekonomi suatu keluarga dengan cara pengaturan kelahiran anak, agar diperoleh suatu keluarga bahagia dan sejahtera yang dapat memenuhi kebutuhan hidupnya. ${ }^{1}$

Pada saat ini pemerintah menyediakan 
secara gratis tiga jenis alokon (alat dan obat kontrasepsi) di seluruh wilayah Indonesia, yaitu kondom, alat kontrasepsi dalam rahim (AKDR) dan susuk KB. Salah satu masalah yang dihadapi oleh para pengguna kontrasepsi adalah masalah efek samping, berupa kenaikan berat badan, pusing, mual, dan sebagainya. ${ }^{2}$ Oleh karena itu, biasanya pengguna kontrasepsi lebih memilih mencari metode kontrasepsi alternatif, yang tidak menimbulkan efek samping, seperti pantang berkala, senggama terputus, atau obat herbal.

Data Badan Kependudukan dan Keluarga Berencana Nasional (BKKBN) menunjukkan metode kontrasepsi perempuan digunakan $(93,66 \%)$ jauh lebih besar dibanding dengan metode kontrasepsi laki-laki (6,34\%). Hal ini menunjukkan bahwa partisipasi laki-laki dalam menggunakan alat kontrasepsi masih sangat kecil. Penggunaan kontrasepsi masih dominan oleh perempuan. ${ }^{3}$

Pepaya (Carica papaya L.) merupakan tanaman yang bernilai ekonomis. Selain harganya murah, hampir semua bagian dari tanaman pepaya ini dapat digunakan untuk keperluan manusia. Ada banyak manfaat yang bisa didapatkan dari tanaman pepaya, antara lain sebagai bahan makanan dan minuman, pakan ternak, bahan kosmetik, industri, serta obat tradisional. Meskipun bagian pepaya lainnya banyak digunakan dalam berbagai bidang, namun manfaat dari biji pepaya belum banyak diketahui. ${ }^{4}$

\section{METODE PENELITIAN}

Penelitian ini mengunakan metode eksperimental analitik dengan pendekatan post-test only control group design. Penelitian dilakukan di Laboratorium Biologi Fakultas Kedokteran Unsrat pada bulan November 2015 sampai Januari 2016. Penelitian dilakukan pada sembilan ekor tikus wistar jantan (Rattus norvegicus) berumur 12 - 15 bulan dengan berat 200 - 250 gram. Sampel dibagi menjadi tiga kelompok yaitu kelompok kontrol $\left(\mathrm{P}_{0}\right)(\mathrm{n}=3)$, kelompok perlakuan 1 $\left(\mathrm{P}_{1}\right)(\mathrm{n}=3)$ dan kelompok perlakuan 2 $\left(\mathrm{P}_{2}\right)(\mathrm{n}=3)$. Kelompok perlakuan 1 dan kelompok perlakuan 2 diberikan ekstrak biji pepaya (Carica papaya L.) dengan dosis masing-masing $50 \mathrm{mg} / \mathrm{kgBB} /$ hari dan $70 \mathrm{mg} / \mathrm{kgBB} /$ hari selama 50 hari. Tikus wistar diberi makan dan minum secara ad libitum.

Rerata konsentrasi dihitung berdasarkan rerata jumlah spermatozoa dalam 1 ml. Penilaian motilitas spermatozoa dilakukan dengan menggunakan kategori A, B, C, dan D. Kategori A adalah spermatozoa yang bergerak cepat dan maju lurus, kategori B adalah spermatozoa yang bergerak lambat atau sulit maju lurus, kategori $\mathrm{C}$ adalah spermatozoa yang bergerak di tempat, dan kategori D adalah spermatozoa yang tidak bergerak. Berdasarkan kategori tersebut, didapatkan rerata motilitas spermatozoa normal dan abnormal, dimana kategori A dan $\mathrm{B}$ adalah rerata motilitas spermatozoa normal sedangkan kategori $\mathrm{C}$ dan $\mathrm{D}$ adalah rerata motilitas spermatozoa abnormal. Penilaian morfologi spermatozoa terbagi menjadi dua yaitu morfologi normal dan abnormal.

Uji normalitas dan homogenitas dilakukan untuk mengetahui distribusi data, kemudian setelah data diketahui berdistribusi normal dan homogen, uji komparabilitas antar kelompok penelitian dilakukan dengan uji $\mathrm{T}$ independen.

\section{HASIL PENELITIAN}

Tabel 1. Rerata Konsentrasi Spermatozoa Tikus Wistar (Rattus norvegicus)

\begin{tabular}{cc}
\hline Kelompok Sampel & $\begin{array}{c}\text { Rerata Konsentrasi } \\
\text { Spermatozoa (x10 } \\
\text { ml) }\end{array}$ \\
\hline Kontrol $\left(\mathrm{P}_{0}\right)$ & \pm 31 \\
Perlakuan $\left(\mathrm{P}_{1}\right)$ & \pm 31 \\
Perlakuan $\left(\mathrm{P}_{2}\right)$ & \pm 34 \\
\hline
\end{tabular}

1. Uji Komparabilitas

Hasil uji normalitas dan homogenitas data menunjukkan bahwa data berdistribusi normal dan homogen. Uji komparabilitas yang digunakan untuk membandingkan kualitas spermatozoa, yaitu konsentrasi 
spermatozoa, motilitas spermatozoa, dan morfologi spermatozoa antar kelompok penelitian adalah Independent-Samples $T$ Test.

Tabel 2. Rerata Presentase Motilitas Spermatozoa Tikus Wistar (Rattus norvegicus)

\begin{tabular}{ccc}
\hline $\begin{array}{c}\text { Kelompok } \\
\text { Sampel }\end{array}$ & $\begin{array}{c}\text { Rerata } \\
\text { Motilitas } \\
\text { Normal } \\
\mathbf{( \% )}\end{array}$ & $\begin{array}{c}\text { Rerata } \\
\text { Motilitas } \\
\text { Abnormal } \\
\mathbf{( \% )}\end{array}$ \\
\hline Kontrol $\left(\mathrm{P}_{0}\right)$ & 85 & 15 \\
Perlakuan $\left(\mathrm{P}_{1}\right)$ & 78,33 & 21,67 \\
Perlakuan $\left(\mathrm{P}_{2}\right)$ & 91,67 & 8 \\
\hline
\end{tabular}

Tabel 3. Rerata Presentase Morfologi Spermatozoa Tikus Wistar (Rattus norvegicus)

\begin{tabular}{ccc}
\hline $\begin{array}{c}\text { Kelompok } \\
\text { Sampel }\end{array}$ & $\begin{array}{c}\text { Rerata } \\
\text { Morfologi } \\
\text { Normal } \\
\text { (\%) }\end{array}$ & $\begin{array}{c}\text { Rerata } \\
\text { Morfologi } \\
\text { Abnormal } \\
\text { (\%) }\end{array}$ \\
\hline Kontrol $\left(\mathrm{P}_{0}\right)$ & 87,33 & 12,67 \\
Perlakuan $\left(\mathrm{P}_{1}\right)$ & 55,33 & 44,67 \\
Perlakuan $\left(\mathrm{P}_{2}\right)$ & 23,67 & 76,33 \\
\hline
\end{tabular}

Tabel 4. Perbandingan Kualitas Spermatozoa

\begin{tabular}{|c|c|c|c|}
\hline $\begin{array}{c}\text { Kualitas } \\
\text { Spermatozoa }\end{array}$ & $\begin{array}{c}\mathbf{P}_{1} \\
\text { terhad } \\
\text { ap } \mathbf{P}_{0} \\
\text { (p) }\end{array}$ & $\begin{array}{c}\mathbf{P}_{2} \\
\text { terhada } \\
\mathbf{p} \mathbf{P}_{0} \\
\text { (p) }\end{array}$ & $\begin{array}{c}\mathbf{P}_{2} \\
\text { terhada } \\
\text { p } \mathbf{P}_{1} \\
\text { (p) }\end{array}$ \\
\hline Kons & 0,097 & 0,371 & 0,878 \\
\hline Motilitas & 0,442 & 0,469 & 0,023 \\
\hline Morfologi & 0,000 & 0,000 & 0,012 \\
\hline
\end{tabular}

Keterangan: Nilai $\mathrm{p}<0,05$ dinyatakan memiliki pengaruh secara signifikan

\section{BAHASAN}

Hasil penelitian ini menunjukkan bahwa kualitas spermatozoa yaitu morfologi normal mengalami penurunan yang signifikan secara statistik sedangkan konsentrasi dan motilitas spermatozoa tidak menunjukkan perubahan.

Pemberian ekstrak biji pepaya (Carica papaya L.) secara statistik menurunkan kualitas spermatozoa dalam aspek morfologi $(p=0,000)$. Pada tabel 3 terlihat adanya penurunan morfologi spermatozoa yang normal, dan rerata morfologi spermatozoa abnormal pada perlakuan 2 menunjukkan peningkatan yang lebih besar daripada perlakuan 1. Hal ini berarti semakin besar dosis ekstrak biji pepaya yang diberikan, maka presentase morfologi spermatozoa yang abnormal akan semakin meningkat.

Abnormalitas morfologi spermatozoa dibagi menjadi dua, yaitu primer dan sekunder. Berdasarkan hasil pengamatan, abnormalitas yang paling banyak ditemukan pada penelitian ini adalah abnormalitas sekunder, yaitu ekor yang terlilit dan patahan pada ekor. Sedangkan abnormalitas primer yang paling banyak dijumpai adalah kelainan leher, seperti tanpa kepala, dan tanpa ekor. Ditemukannya abnormalitas primer diduga karena adanya gangguan spermatogenesis pada fase spermiogenesis, yaitu saat pembentukan spermatozoa dari spermatid, sedangkan abnormalitas sekunder diduga karena terjadi gangguan pada saat maturasi spermatozoa di epididimis. ${ }^{5}$

Penelitian sebelumnya menunjukkan bahwa peningkatan morfologi spermatozoa abnormal terjadi karena ekstrak biji pepaya menyebabkan terjadinya abnormalitas organela sel pada bagian leher spermatozoa, yaitu vakuolisasi pada mitokondria. Hal ini menyebabkan fungsi mitokondria dalam menghasilkan energi menjadi tidak maksimal, dan dengan demikian berpengaruh pada motilitas spermatozoa. ${ }^{6}$ Pada penelitian ini tidak ditemukan perubahan motilitas secara signifikan pada pemberian ekstrak biji pepaya diduga karena dosis pemberian belum cukup untuk menyebabkan penurunan motilitas spermatozoa normal secara signifikan walaupun sudah terdapat pengaruh terhadap morfologi spermatozoa.

Kandungan enzim papain di dalam ekstrak biji papaya juga dapat menurunkan total lipid pada jaringan testis dan epididimis. Ekstrak biji pepaya menurunkan aktivitas enzim lipase lipoprotein dan menghambat absorpsi nutrisi dari sistem gastrointestinal, sedangkan energi yang dihasilkan dari nutrisi tersebut diperlukan untuk proses spermatogenesis di testis dan maturasi 
spermatozoa di epididimis. ${ }^{7}$

Tidak ada perubahan secara signifikan terhadap konsentrasi spermatozoa menunjukkan bahwa proliferasi pada spermatogenesis tidak terganggu, sehingga pada penelitian ini, penurunan morfologi spermatozoa normal diduga karena terjadi gangguan pada saat maturasi spermatozoa di epididimis.

Berdasarkan hasil penelitian ini, maka ekstrak biji pepaya dapat digunakan sebagai kontrasepsi alami bagi pria, karena efeknya yang mempengaruhi morfologi spermatozoa. Selain itu ekstrak biji pepaya ini murah, mudah didapatkan, dan dapat diterima oleh masyarakat.

\section{SIMPULAN}

Terjadi penurunan kualitas spermatozoa dalam aspek morfologi pada kelompok perlakuan 1 dan perlakuan 2 yang diberikan ekstrak biji pepaya (Carica papaya L.) terhadap kelompok kontrol yang tidak diberikan ekstrak biji pepaya (Carica papaya L.)

\section{SARAN}

1. Perlu dilakukan penelitian lanjutan untuk membuktikan efek antifertilitas dari biji pepaya.

2. Perlu dilakukan penelitian selanjutnya dengan dosis yang lebih besar dan waktu penelitian yang lebih lama.

\section{DAFTAR PUSTAKA}

1. Undang-undang Republik Indonesia Nomor 52 tahun 2009. Perkembangan Kependudukan dan Pembangunan Keluarga.

2. Survei Demografi dan Kesehatan Indonesia 2007. Dapat diakses di http://www.depkes.go.id/download.p hp?file=download/pusdatin/buletin/bu letin-kespro.pdf

3. Proporsi metode kontrasepsi menurut jenis kelamin, BKKBN 2014. Dapat diakses di http://www.depkes.go.id/download.p hp?file=download/pusdatin/infodatin/ infodatin-harganas.pdf

4. Siburian J, Marlina J, Johari A. Pengaruh ekstrak biji pepaya (Carica papaya L.) pada tahap prakopulasi terhadap fungsi reproduksi mencit (Mus musculus, L.) swiss webster betina. 2008; $1: 1-5$

5. Ermayanti NGA, Manik, dan Rai SNM. Kualitas Spermatozoa Mencit (Mus musculus L.) Setelah Perlakuan Infusa Kayu Amargo (Quassia amara Linn.) dan Pemulihannya. J Biol. 2010; 14(1), 45-49.

6. Lohiya NK, Goyal RB, Jayaprakash D, Ansari AS, dan Sharma S. Antifertility Effects of Aquoeous Extract of Carica papaya Seed in Male Rats. Planta Med. 1999; 60, 400-404.

7. Basha SH dan Cangamma C. Effect of Carica papaya (L.) Seed on Lipid Metabolites in Male Albino Rats. Int J Pharm Sci. 2013; 5(4), 527 - 529 